\title{
Overproduction of Uric Acid in Hypoxanthine-Guanine Phosphoribosyltransferase Deficiency
}

\author{
CONTRIBUTION BY IMPAIRED PURINE SALVAGE
}

\author{
N. LAWRENCE EdWARDS, DAVID RECKER, and IRving H. Fox, Human Purine Research \\ Center, Departments of Internal Medicine and Biological Chemistry, Clinical \\ Research Center, University of Michigan Medical Center, Ann Arbor, \\ Michigan 48109
}

A B S T RACT The contribution of reduced purine salvage to the hyperuricemia associated with hypoxanthine-guanine phosphoribosyltransferase deficiency was measured by the intravenous administration of tracer doses of $\left[8{ }^{14} \mathrm{C}\right]$ adenine to nine patients with normal enzyme activity, three patients with a partial deficiency of hypoxanthine-guanine phosphoribosyltransferase, and six patients with the Lesch-Nyhan syndrome. The mean cumulative excretion of radioactivity $7 \mathrm{~d}$ after the adenine administration is $5.6 \pm 2.4$, $12.9 \pm 0.9$, and $22.3 \pm 4.7 \%$ of infused radioactivity for control subjects, partial hypoxanthine-guanine phosphoribosyltransferase-deficient subjects, and LeschNyhan patients, respectively. To assess relative rates of nucleotide degradation in control and hypoxanthineguanine phosphoribosyltransferase-deficient patients two separate studies were employed. With $\left[8-{ }^{14} \mathrm{C}\right]$ inosine administration, three control subjects excreted $3.7-8.5 \%$ and two enzyme-deficient patients excreted $26.5-48.0 \%$ of the injected radioactivity in $18 \mathrm{~h}$. The capacity of the nucleotide catabolic pathway to accelerate in response to D-fructose was evaluated in control and enzymedeficient patients. The normal metabolic response to intravenous fructose is a $7.5 \pm 4.2-\mathrm{mmol} / \mathrm{g}$ creatinine increase in total urinary purines during the 3 - $h$ after the infusion. The partial hypoxanthine-guanine phosphoribosyltransferase-deficient subjects and Lesch-Nyhan patients show increases of $18.6 \pm 10.8$ and $17.3 \pm 11.8$ $\mathrm{mmol} / \mathrm{g}$ creatinine, respectively. Of the observed rise in purine exretion in control subjects, $40 \%$ occurs from

Dr. Edwards is a Rheumatology Fellow from the Rackham Arthritis Research Unit supported by training grant USPHA AM 07080-02.

Address reprint requests to Dr. Fox.

Received for publication 22 May 1978 and in revised form 27 December 1978. inosine excretion and 32\% occurs from oxypurine excretion. The rise in total purine excretion with LeschNyhan syndrome is almost entirely accounted for by an elevated uric acid excretion. Increases in urine radioactivity after fructose infusion are distributed in those purines that are excreted in elevated quantities.

The observations suggest that purine salvage is a major contributor to increased purine excretion and that the purine catabolic pathway responds differently to an increased substrate load in hypoxanthine-guanine phosphoribosyltransferase deficiency. The purine salvage pathway is normally an important mechanism for the reutilization of hypoxanthine in man.

\section{INTRODUCTION}

The deficiency of hypoxanthine-guanine phosphoribosyltransferase is associated with massive overproduction and overexcretion of uric acid (1-3). The mechanism for excessive uric acid synthesis in this disorder has been investigated in vivo by measuring the enrichment of uric acid by isotopic glycine $(2,4,5)$. Incorporation of glycine into the purine ring during de novo synthesis $(2,4,5)$ labels inosine- $5^{\prime}$-monophosphate $(\mathrm{IMP})^{1}$ that can then be degraded to inosine, hypoxanthine, xanthine, and uric acid (Fig. 1). The 20-fold increase in the rate of incorporation of $\left[{ }^{14} \mathrm{C}\right]$ glycine into urinary uric acid in the deficiency of hypoxanthine-guanine phosphoribosyltransferase is believed to result from a 20 -fold elevation in the rate of purine biosynthesis de novo (2).

The explanation of excessive uric acid production on the basis of increased de novo purine synthesis does not emphasize a potentially important contributor to

${ }^{1}$ Abbreviation used in this paper: IMP, inosine-5'-monophosphate. 
uric acid overproduction in hypoxanthine-guanine phosphoribosyltransferase deficiency. The absence of this enzyme leads to an inability to resynthesize IMP from hypoxanthine. As a result, any hypoxanthine formed in this disorder can only be oxidized to uric acid. Because the amount of hypoxanthine reutilization in normal man is not known, the relative contribution of absent hypoxanthine reutilization to increased uric acid production in hypoxanthine-guanine phosphoribosyltransferase deficiency has not been measured in vivo. The formation of $\left[{ }^{14} \mathrm{C}\right]$ uric acid from $\left[{ }^{14} \mathrm{C}\right]$ glycine in man involves $\left[{ }^{14} \mathrm{C}\right]$ hypoxanthine synthesis as an intermediary step (Fig. 1). Thus, the previously observed increase in the rate of glycine incorporation into uric acid may reflect decreased hypoxanthine reutilization as well as accelerated de novo synthesis.

To assess the relative contribution of a disorder of hypoxanthine salvage to uric acid overproduction in hypoxanthine-guanine phosphoribosyltransferase deficiency, we have used $\left[8-{ }^{-14} \mathrm{C}\right]$ adenine or $\left[8-{ }^{14} \mathrm{C}\right]$ inosine administration to compare this pathway isolated from de novo synthesis in subjects with deficient or normal enzyme activity. Our observations suggest that decreased hypoxanthine reutilization is an important contributor to uric acid overproduction in this enzyme deficiency.

\section{METHODS}

Tetrasodium phosphoribosylpyrophosphate, D-fructose, uricase, xanthine oxidase, AMP, IMP, adenine, and purine nucleoside phosphorylase were purchased from the Sigma Chemical Co., St. Louis, Mo. Xanthine and hypoxanthine were purchased from Calbiochem-Behring Corp., American Hoechst Corp., San Diego, Calif. Charcoal was obtained from Barnebey-Cheney Co., Columbus, Ohio. From Amersham Corp., Arlington Heights, Ill., we purchased $\left[8{ }^{-14} \mathrm{C}\right]$ hypoxanthine $(50 \mathrm{mCi} / \mathrm{mmol})$ and $\left[8-{ }^{14} \mathrm{C}\right]$ inosine $(50 \mathrm{mCi} / \mathrm{mmol})$. From New England Nuclear Corp., Boston, Mass., we purchased $\left[8-{ }^{14} \mathrm{C}\right]$ adenine $(52 \mathrm{mCi} / \mathrm{mmol})$. In line Cathivex filter units $(0.22$ and $0.45 \mu \mathrm{m})$ were obtained from Millipore Corp., Bedford, Mass. All other reagents were of the highest quality commercially available.

10 hyperuricemic patients with normal erythrocyte hypoxanthine-guanine phosphoribosyltransferase, 6 patients with a partial deficiency of this enzyme, and 6 patients with the Lesch-Nyhan syndrome were admitted to the Clinical Research Center at the University of Michigan Medical Center. Nine of the control patients had inactive gouty arthritis and one had recurrent renal calculi (Table I). The patients with a partial enzyme deficiency had gout and(or) renal calculi, whereas the other six patients had Lesch-Nyhan syndrome (Table I). Informed consent was obtained from all adult patients and from the parents of children. Each patient received a weight maintenance, purine-free diet with $10-12 \%$ protein 5-7 d before and throughout the study period. No medication that might affect uric acid synthesis or excretion was given.

$10-25 \mu \mathrm{Ci}$ of $\left[8^{-14} \mathrm{C}\right]$ adenine contained in $2-5 \mu \mathrm{mol}$ of adenine was administered intravenously through Cathivex filters. The filters were flushed with $40 \mathrm{ml}$ of $0.87 \%$ sodium chloride to insure delivery of the entire isotope dose. Daily urine collections were obtained over the following $1-3 \mathrm{wk}$.
An aliquot consisting of $0.5 \mathrm{ml}$ of each urine sample was spotted on Whatman 3MM chromatographic paper (Whatman, Inc., Clifton, N. J.) and counted in a Packard model 3003 liquid scintillation spectrometer (Packard Instruments Co., Inc., Downers Grove, Ill.). The total amount of radioactivity excreted each day was calculated and this value was factored by the total amount of radioactivity infused to determine the percentage of excretion. Similar isotope infusion studies were carried out with $\left[8-{ }^{14} \mathrm{C}\right]$ inosine. $10 \mu \mathrm{Ci}$ of $\left[{ }^{14} \mathrm{C}\right]$ inosine contained in $1 \mu \mathrm{mol}$ of inosine was infused intravenously through $0.22 \mu \mathrm{M}$ Cathivex filter. Urine was collected at 2- to 3 -h intervals for the $36 \mathrm{~h}$ after inosine infusion. Urinary radioactivity was determined by the method described above for $\left[8-{ }^{14} \mathrm{C}\right]$ adenine infusion.

3-5 d after radioactive adenine administration, all patients received fructose $(0.5 \mathrm{~g} / \mathrm{kg})$ intravenously over $10 \mathrm{~min}$ as described $(6,7)$. Blood for plasma urate determination was obtained at $0,15,30,60,90$, and 150 min after the start of the intravenous fructose. Urine for creatinine, radioactivity, and purine assay was obtained at hourly intervals for $1 \mathrm{~h}$ before and $3 \mathrm{~h}$ after fructose infusion.

Purines were extracted from urine using activated charcoal. $10-20 \mathrm{ml}$ of each urine sample were suspended in $0.5-1.0 \mathrm{ml}$ of washed, activated charcoal for $15 \mathrm{~min}$ and then filtered through a Buchner funnel. This procedure was repeated twice to bind all purine compounds to the charcoal. These substances were then eluted from the charcoal by washing eight times with $5 \mathrm{ml}$ of $50 \%$ ethanol and $3 \% \mathrm{NH}_{4} \mathrm{OH}$. The efficiency of the charcoal-binding technique was tested in urines from patients previously given intravenous $\left[8^{-14} \mathrm{C}\right]-$ adenine. Of the total urine radioactivity, $96 \%$ bound to the charcoal and $81 \%$ could subsequently be eluted with the ethanol and ammonium hydroxide washes. In separate experiments, the specific binding and elution characteristics of individual purine compounds was determined by adding known quantities of purine break down products to normal urine. Uric acid, hypoxanthine, and inosine all bind to charcoal with $>95 \%$ efficiency. Elution washes resulted in 93,74 , and $90 \%$ recovery of the initial quantity of added purines for uric acid, hypoxanthine, and inosine respectively. The elutant was evaporated to dryness in a Matheson oven at $40^{\circ} \mathrm{C}$ (Matheson Gas Products, East Rutherford, N. J.). The residue was resuspended in $1.5 \mathrm{ml}$ of $0.05 \mathrm{~N} \mathrm{NaOH}$ and applied to a Bio-Gel P-2 column (Bio-Rad Laboratories, Richmond, Calif.) $1.6 \times 60 \mathrm{~cm}$ equilibrated with $50 \mathrm{mM}$ sodium borate, pH 9.1. 1-ml fractions were collected in a LKB 700 ultrarac fraction collector (LKB Instruments, Inc., Rockville, Md.). The radioactivity of each sample was determined by spotting $400 \mu \mathrm{l}$ on chromatographic paper and counting in a Packard model 3003 liquid scintillation spectrometer system (Packard Instruments Co.). The ultraviolet absorbance of each fraction was measured at 258 and $280 \mathrm{~nm}$ on a Cary spectrophotometer (Cary Instruments, Fairfield, N. J.). The fractions were pooled and assayed specifically for uric acid, hypoxanthine, xanthine, and inosine by enzymatic spectrophotometric methods.

Hypoxanthine-guanine and adenine phosphoribosyltransferases were determined by radiochemical methods (8). Serum urate and urinary uric acid and oxypurines were quantitated by enzymatic spectrophotometric methods $(9,10)$. Urinary inosine was measured by an enzymatic spectrophotometric assay developed in our laboratory. ${ }^{2}$ Urine is diluted 1:9 in $67 \mathrm{mM}$ glycine, $\mathrm{pH}$ 9.4. Uricase is then added and this mixture is incubated at $25^{\circ} \mathrm{C}$ for $2 \mathrm{~h}$ to remove any uric acid present in the urine. The uricase is subsequently

${ }^{2}$ Andres, C. M., and I. H. Fox. Unpublished results. 
TABLE I

Study Subjects

\begin{tabular}{|c|c|c|c|c|c|c|}
\hline Patient & Age & $\begin{array}{c}\text { Erythrocyte } \\
\text { HGPRT** } \\
(n=54-120)\end{array}$ & $\begin{array}{l}\text { Plasma } \\
\text { urate }\end{array}$ & $\begin{array}{l}\text { Total urinary } \\
\text { purine } \\
\text { excretion }\end{array}$ & $\begin{array}{l}\text { Carbon-14t } \\
\text { excretion }\end{array}$ & Clinical status \\
\hline & $y r$ & nmol/h/mg & $m g / d$ & $\begin{array}{c}\text { mmol/g } \\
\text { creatinine }\end{array}$ & $\%$ totalluk & \\
\hline \multicolumn{7}{|c|}{ Normal enzyme activity } \\
\hline G.Sh. & 72 & 110.0 & 8.1 & 1.5 & 1.7 & Chronic gout, tophi \\
\hline M.B. & 62 & 90.2 & 7.5 & 1.8 & 6.4 & Chronic gout \\
\hline M.F. & 64 & 85.6 & 11.5 & 1.7 & 4.2 & Chronic gout, tophi \\
\hline F.H. & 42 & 111.3 & 7.0 & 2.1 & 5.4 & Chronic gout, tophi \\
\hline R.Mc. & 62 & 85.3 & 12.0 & 2.3 & 8.8 & Chronic gout, tophi \\
\hline D.P. & 37 & 91.6 & 10.5 & 1.8 & 3.7 & Chronic gout \\
\hline N.P. & 49 & 84.7 & 9.1 & 1.7 & 4.8 & Chronic gout \\
\hline T.W. & 52 & 118.4 & 6.4 & 0.7 & 6.1 & Chronic gout, tophi \\
\hline J.Sn. & 63 & 86.3 & 8.9 & 3.5 & - & Chronic gout, tophi \\
\hline B.L. & 48 & 93.1 & 6.5 & 2.9 & 9.4 & Recurrent renal calculi \\
\hline \multicolumn{7}{|c|}{ Lesch-Nyhan syndrome } \\
\hline C.F. & 14 & $N D \S$ & 8.8 & 21.7 & 19.7 & $\begin{array}{l}\text { Hyperuricemia, mental retarda- } \\
\text { tion, spasticity, self-mutilation, } \\
\text { choreoathetosis }\end{array}$ \\
\hline J.H. & 9 & $N D \S$ & 8.3 & 13.7 & 17.4 & Same as C.F. \\
\hline W.S. & 4 & 0.54 & 9.9 & 16.2 & 31.2 & Same as C.F. \\
\hline E.S. & 17 & 0.59 & 9.9 & 11.4 & 22.3 & Same as C.F. \\
\hline R.S. & 16 & 0.09 & 7.1 & 11.3 & 21.0 & Same as C.F. \\
\hline B.M. & 15 & 0.02 & 9.1 & 10.5 & 22.3 & Same as C.F. \\
\hline \multicolumn{7}{|l|}{ Partial HGPRT } \\
\hline G.Sm. & 26 & 38.4 & 11.3 & 3.1 & 11.8 & Gout and nephrolithiasis \\
\hline Mark D. & 19 & 0.27 & 15.6 & 5.9 & 13.1 & Hematuria and hyperuricemia \\
\hline Mike D. & 17 & 1.32 & 12.0 & 6.0 & 13.7 & Hyperuricemia \\
\hline R.D. & 6 & 0.32 & 8.2 & 12.8 & - & Hematuria and hyperuricemia \\
\hline K.C. & 11 & 14.5 & 9.9 & 7.9 & - & Nephrolithiasis and hyperuricemia \\
\hline T.C. & 9 & 14.8 & 13.9 & 6.6 & - & Nephrolithiasis and hyperuricemia \\
\hline
\end{tabular}

* Hypoxanthine-guanine phosphoribosyltransferase.

\$ Carbon-14 for the week after infusion of $\left[8-{ }^{14} \mathrm{C}\right]$ adenine expressed as a percentage of total radioactivity infused.

$\S$ Not detectable by our assay.

inactivated by heating the sample to $95^{\circ} \mathrm{C}$ for $4 \mathrm{~min} .50 \mathrm{mM}$ potassium phosphate, $\mathrm{pH} 7.4$, is added resulting in a final 1:29 dilution of the urine. $20 \mathrm{ml}$ of xanthine oxidase is added to $3 \mathrm{ml}$ of the diluted urine sample to convert oxypurines (xanthine and hypoxanthine) to uric acid. After the spectrophotometric absorption at $292 \mathrm{~nm}$ is stabilized, $20 \mu \mathrm{l}$ of purine nucleoside phosphorylase (1:9 dilution) is added to the reaction. Urinary inosine and deoxyinosine are converted to uric acid with the subsequent increase in optical density at wavelength $292 \mathrm{~nm}$. The increase of absorbance at $292 \mathrm{~nm}$ quantitates the amount of uric acid produced from inosine.

Creatinine was measured by an automated modified Jaffe reaction (11). Protein was estimated by the method of Lowry et al. (12) with crystalline bovine serum albumin as a standard. The concentrations of compounds used in these studies were based on description or assay provided by the manufacturer.

\section{RESULTS}

\section{Urinary radioactivity}

Hypoxanthine reutilization was evaluated by the excretion of urinary radioactivity after the intravenous administration of tracer doses of $\left[8-{ }^{14} \mathrm{C}\right]$ adenine. The radioactive adenine is incorporated into the adenine nucleotide pool. $1 \%$ of the administered radioactivity is excreted into the urine each day in normal patients (13-15). This represents that fraction of the adenine nucleotide pool that is degraded daily to hypoxanthine and then to uric acid. A major alteration in the reutilization of $\left[8-{ }^{14} \mathrm{C}\right]$ hypoxanthine to IMP may be reflected in a change in the synthesis of $\left[8-{ }^{14} \mathrm{C}\right]$ uric acid (Fig. 1). The technique of $\left[8-{ }^{14} \mathrm{C}\right]$ adenine infusion allows the quantitation of hypoxanthine salvage separate from purine biosynthesis de novo.

Nine subjects with normal hypoxanthine-guanine phosphoribosyltransferase activity excrete $0.8 \%$ of the administered radioactive dose each day. The mean cumulative excretion for the 1 st wk after $\left[8-{ }^{14} \mathrm{C}\right]$ adenine infusion is $5.6 \pm 2.4 \%$ (Fig. 2). Six patients with the Lesch-Nyhan syndrome have a mean cumulative excretion of $22.3 \pm 4.7 \%$ for the 1 st wk, whereas three 


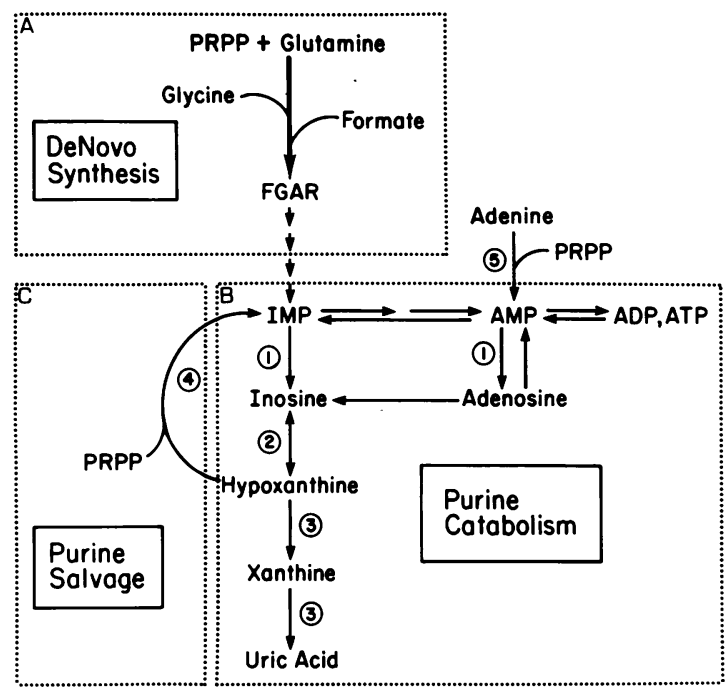

FIGURE 1 Purine metabolic pathway. Intracellular purine nucleotide pool is maintained by interdependent metabolic processes. (A) De novo biosynthesis is a pathway for the synthesis of the purine ring from nonpurine precursors. Availability of phosphoribosylpyrophosphate (PRPP) is ratelimiting in this synthetic process. (B) Purine nucleotide catabolism proceeds through 5'-nucleotidase (1), purine nucleoside phosphorylase (2), and xanthine oxidase (3) to form the catabolic end product in humans, uric acid. (C) Purine salvage is catalyzed by hypoxanthine-guanine phosphoribosyltransferase (4) and adenine phosphoribosyltransferase (5). The salvage reactions allow the conversion of purine bases to their respective nucleotides. A deficiency of hypoxanthineguanine phosphoribosyltransferase (4) leads to a loss of the ability to reutilize hypoxanthine, so that all of this compound formed is oxidized to uric acid. The use of isotopic adenine labels the adenine nucleotide pool. The amount of degradation of radioactive adenine nucleotides to labeled uric acid will be dependent upon the quantity of hypoxanthine salvage. FGAR, formylglycineamide ribonucleotide.

patients with a partial deficiency of hypoxanthineguanine phosphoribosyltransferase have a mean cumulative excretion of $12.9 \pm 0.9 \%$ (Fig. 2). Because of the age difference between the patient groups, one cannot rule out an influence of this variable on the results.

\section{Basis for increased radioactivity excretion}

The excretion of radioactivity in the urine after the radiolabeling of the adenine nucleotide pool with $\left[8-{ }^{14} \mathrm{C}\right]$ adenine is markedly increased when hypoxanthine-guanine phosphoribosyltransferase is deficient. This may reflect diminished reutilization of hypoxanthine to IMP (Fig. 1). However, an alternative interpretation of these observations may be an increase in the rate of adenine nucleotide degradation in the enzyme-deficient subjects. These possibilities were examined by further studies.

Decreased reutilization of hypoxanthine. To further assess. for reutilization of hypoxanthine, $\left[8-{ }^{14} \mathrm{C}\right]$ inosine was administered to normal and enzyme deficient subjects. Because inosine can only be converted to hypoxanthine, decreased hypoxanthine reutilization in enzyme-deficient patients would be indicated by a rapid excretion of the radioactivity associated with this compound and its break down products (Fig. 1), The excretion of radioactivity should not be affected by the rate of nucleotide degradation. After $18 \mathrm{~h}$, the normal subjects excreted $3.7-8.5 \%$ of the administered radioactivity, whereas the patients with enzyme deficiency excreted 26.5 and $48.0 \%$ (Table II). These observations provide further evidence for the existence of decreased hypoxanthine salvage in hypoxanthineguanine phosphoribosyltransferase deficiency.

Increased nucleotide degradation. There remains the possibility that accelerated purine nucleotide degradation accounts for a component of the increased radioactivity excretion after $\left[8{ }^{14} \mathrm{C}\right]$ adenine administration. Therefore, an attempt was made to compare this pathway in the three groups of subjects under the conditions of acute substrate load caused by the rapid infusion of fructose. The latter results in a cascade of purine nucleotide degradation as a result of the depletion of intracellular ATP and inorganic phosphate during the hepatic phosphorylation of fructose $(6,16-24)$. If there is increased degradation of the adenine nucleotide pool under basal conditions in hypoxanthine-guanine phosphoribosyltransferase deficiency this may be reflected by an inability to excrete as large a quantity of purines into the urine as is excreted by control subjects.

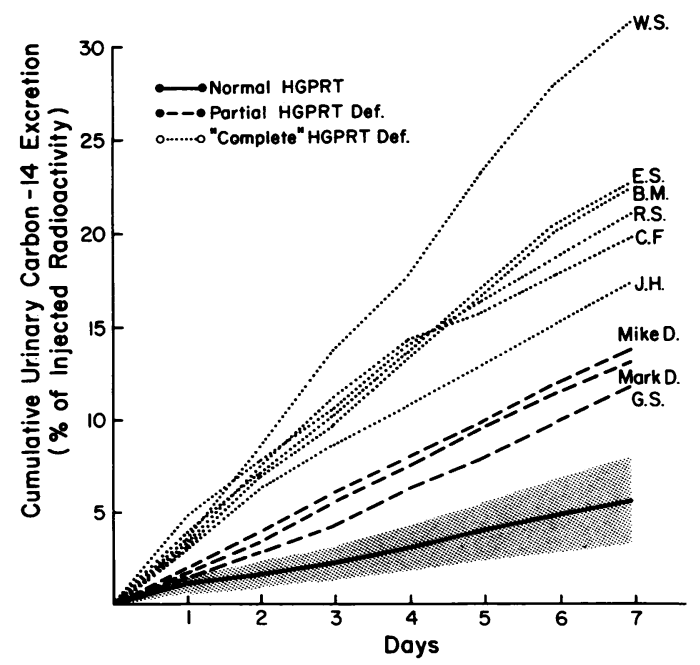

FIGURE 2 Cumulative carbon-14 excretion after $\left[8-{ }^{14} \mathrm{C}\right]-$ adenine. Nine adult patients with normal levels of hypoxanthine-guanine phosphoribosyltransferase excreted $5.6 \pm 2.4 \%$ of the administered radioactivity in the 7 - $\mathrm{d}$ after intravenous $\left[8-{ }^{14} \mathrm{C}\right]$ adenine. Six patients with Lesch-Nyhan syndrome excreted $22.3 \pm 4.7 \%$ in $7 \mathrm{~d}$, and three patients with partial hypoxanthine-guanine phosphoribosyltransferase deficiency had intermediate radioactivity excretion of $12.9 \pm 0.7 \%$. 
TABLE II

Urinary Radioactivity Excretion after $\left[8^{-14} \mathrm{C}\right]$ Inosine Administration

\begin{tabular}{lcc}
\hline \multicolumn{1}{c}{ Patient } & $\begin{array}{c}18 \text { h cumulative } \\
{ }^{4} \text { C-excretion }\end{array}$ & Mean \\
\hline & $\begin{array}{c}\text { \% of infused } \\
\text { radioactivity }\end{array}$ & \\
Normal enzyme activity & & \\
C.G. & 3.7 & 6.4 \\
J.A. & 7.0 & \\
W.K. & 8.5 & \\
Enzyme deficiency & & \\
E.S. & 48.0 & 37.2 \\
W.S. & 26.5 & \\
\hline
\end{tabular}

Urinary excretion of radioactivity was measured during the first $18 \mathrm{~h}$ after $\left[8-{ }^{14} \mathrm{C}\right]$ inosine infusion in three patients with normal hypoxanthine-guanine phosphoribosyltransferase and two patients with Lesch-Nyhan syndrome.

The three groups of patients studied demonstrate a similar rapid elevation of plasma urate to near peak levels within $30 \mathrm{~min}$ of the fructose administration (Fig. 3). Base-line plasma urate concentrations in seven control subjects increased by $1.6 \pm 0.8 \mathrm{mg} / \mathrm{dl}$, by $2.2 \pm 1.0$ in six patients with partial enzyme deficiency, and by $2.1 \pm 0.3 \mathrm{mg} / \mathrm{dl}$ in six patients with complete enzyme deficiency.

Urinary total purine excretion is increased after D-fructose administration in all patients studied, although the pattern of purine compounds excreted is altered in the enzyme-deficient subjects (Fig. 4). The increase in total urinary purine excretion $3 \mathrm{~h}$ after intravenous fructose is $7.5 \pm 4.2,18.6 \pm 10.8$, and $17.3 \pm 11.8 \mathrm{mmol} / \mathrm{g}$ creatinine in seven control subjects, six patients with a partial enzyme deficiency, and six patients with the Lesch-Nyhan syndrome, respectively. $73 \%$ of this increase of purine excretion is accounted for by inosine

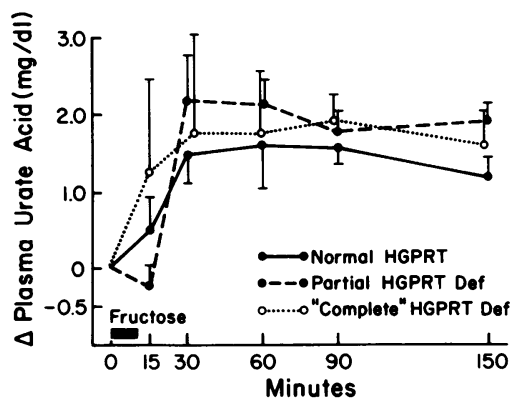

Figure 3 Postfructose plasma urate elevation. Seven control subjects, six patients with partial hypoxanthine-guanine phosphoribosyltransferase deficiency, and six patients with Lesch-Nyhan syndrome had base-line plasma urate levels of $8.7 \pm 2.1$, $11.8 \pm 2.7$, and $8.8 \pm 1.1$, respectively. A similar response in plasma urate to $D$-fructose $(0.5 \mathrm{~g} / \mathrm{kg})$ was observed in all three groups.
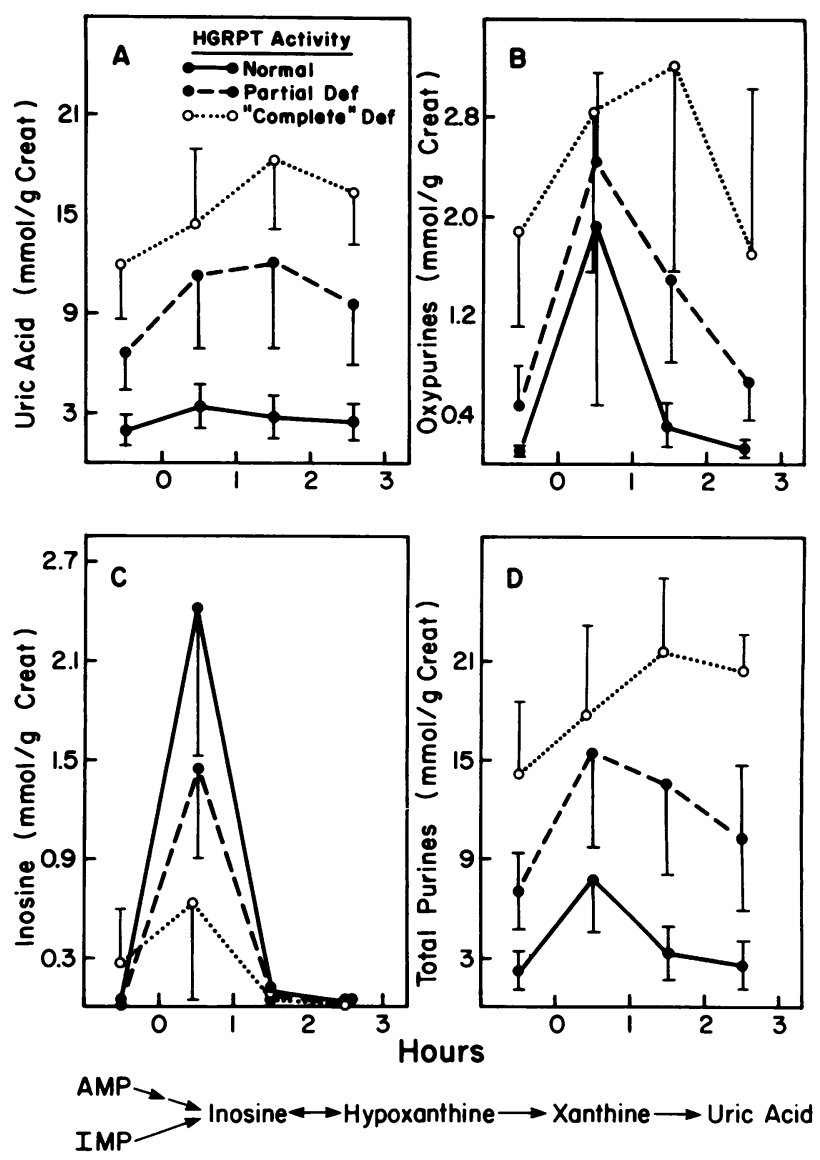

FIGURE 4 Urinary purine excretion after fructose infusion. Alteration of urinary purine excretion was observed in control subjects $(n=7)$, partial hypoxanthine-guanine phosphoribosyltransferase deficiency $(n=6)$ and Lesch-Nyhan syndrome $(n=6)$ for the $1 \mathrm{~h}$ before and $3 \mathrm{~h}$ postintravenous $\mathrm{D}$-fructose $(0.5 \mathrm{~g} / \mathrm{kg}$ ). (A) Urinary uric acid; (B) urinary oxypurines (hypoxanthine and xanthine); (C) urinary inosine; and (D) total urinary purines (uric acid, xanthine, hypoxanthine, and inosine). Values expressed are the mean $\pm S D$ for each group. The abridged purine catabolic pathway at the bottom of this figure depicts the progression of nucleotide breakdown after D-fructose.

and hypoxanthine in subjects with normal enzyme activity, whereas virtually all the increase of purine excretion in enzyme-deficient patients is accounted for by elevated uric acid excretion (Fig. 4). The increased purine excretory response to a fructose infusion in the enzyme-deficient subjects suggest a full potential to increase purine nucleotides degradation. The modified pattern of purine excretion may indicate quantitative changes in the purine catabolic enzymes.

Radioactivity excretion in the urine after fructose infusion corresponds directly with those purine compounds that are increased absolutely in normal subjects and patients with Lesch-Nyhan syndrome. When the control subjects are given tracer doses of $\left[8{ }^{14} \mathrm{C}\right]$ adenine, urinary radioactivity is predominantly in uric acid. 
After a fructose infusion, the increased radioactivity is associated with inosine and to a lesser extent with hypoxanthine (Fig. 5B). In patients with Lesch-Nyhan syndrome, there is little difference in the profile of purine composition or the amount of radioactivity appearing in urine before and after fructose infusion (Fig. 6C and D). The radioactivity in these urines represents uric acid with only a minor contribution by hypoxanthine. The urinary purine profile and radioactivity distribution in the subjects with partial deficiency of hypoxanthine-guanine phosphoribosyltransferase is markedly different from the patterns of normal or Lesch-Nyhan subjects. Only $30 \%$ of the radioactivity in the base-line urines (Fig. 6A) could be accounted for in the usual measured purine pools (uric acid, xanthine, hypoxanthine, and inosine). The majority of the radioactivity in these urines was eluted from the Bio-Gel P-2 column in specific peaks, but the metabolic products in these radioactive fractions have not yet been determined. It is possible that the higher serum urate levels associated with the partial enzyme deficiency may lead to an increased amount of uric acid oxidation by intestinal bacteria. The major catabolic product, allantoin, and its many oxidative products may be reabsorbed into the body and excreted in the urine.

\section{DISCUSSION}

Two purine salvage enzymes in man catalyze the transfer of the ribose-5-phosphate moiety of phospho-

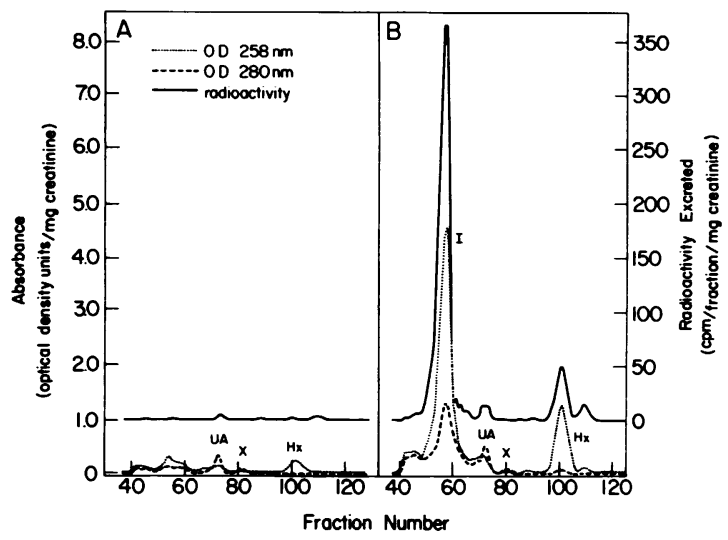

FIGURE 5 Effect of D-fructose on urinary radioactivity and purine excretion in a control patient. $4 \mathrm{~d}$ after $\left[8^{-14} \mathrm{C}\right]$ adenine infusion, urine samples were obtained from control subject and fractionated over a Bio-gel column. Each fraction was tested for absorbance at 258 and $280 \mathrm{~nm}$ and radioactive content. (A) Prefructose infusion. Low levels of uric acid (UA), xanthine $(\mathrm{X})$, and hypoxanthine $(\mathrm{Hx})$ with small amount of radioactivity present in UA fraction. (B) Postfructose. Large increase in radioactivity corresponds to inosine (I) fraction with relatively small increases in UA, $\mathrm{X}$, and Hx. Results are expressed per milligram of creatinine in the original urine volume.

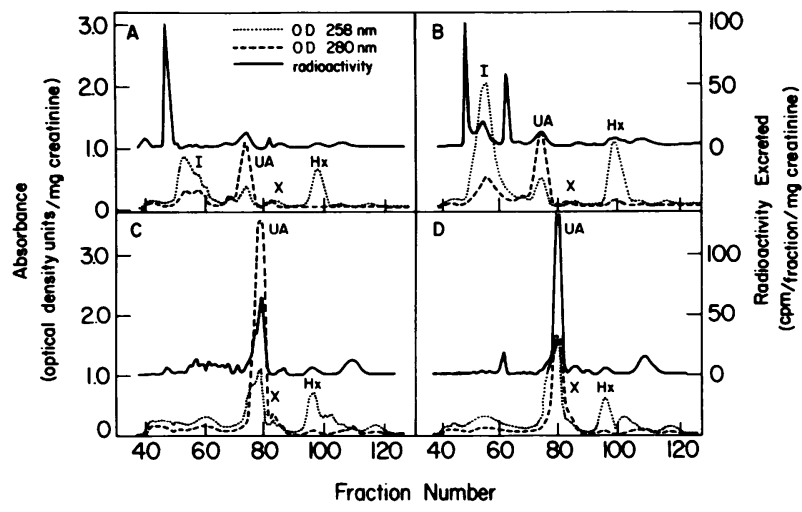

FIGURE 6 Effect of D-fructose on urinary radioactivity and purine excretion in hypoxanthine-guanine phosphoribosyltransferase deficiency. The format is similar to Fig. 5. (A) Partial hypoxanthine-guanine deficiency prefructose. (B) Partial hypoxanthine-guanine phosphoribosyltransferase deficiency postfructose. Increased radioactivity appears in inosine (I) fraction. (C) Lesch-Nyhan syndrome. High levels of radioactivity in uric acid (UA) fraction. (D) Lesch-Nyhan syndrome postfructose. No change in purine profile with radioactivity remaining in UA fraction.

ribosylpyrophosphate to a purine base, forming the corresponding nucleoside $5^{\prime}$-monophosphate $(25,26)$ (Fig. 1). The highest levels of these enzymes are found in cells with limited capacity for de novo purine production, such as erythrocytes, nerve cells, and leukocytes (27-29). The actual contribution of purine salvage enzymes to nucleotide synthesis in man was not appreciated until the discovery of the hypoxanthineguanine phosphoribosyltransferase deficiency in the Lesch-Nyhan syndrome (30). Investigations of the hyperuricemia in this disorder appeared to indicate an elevated rate of purine synthesis de novo on the basis of a 20 -fold increase in the rate of incorporation of $\left[{ }^{14} \mathrm{C}\right]$ glycine into urinary uric acid $(2-4)$. The rate of de novo purine synthesis is elevated only by threeto fourfold with the more specific method of $\left[{ }^{14} \mathrm{C}\right]$ formate incorporation into formylglycineamide ribonucleotide in enzyme-deficient cultured fibroblasts and lymphoblasts (31-33). This increased rate of purine biosynthesis de novo is explained by a rise in the concentration of intracellular phosphoribosylpyrophosphate, a ratelimiting substrate for this pathway (34).

Interest in the contribution of increased purine biosynthesis de novo to the elevated uric acid production in hypoxanthine-guanine phosphoribosyltransferase deficiency has tended to minimize a possible role for reduced hypoxanthine reutilization. In fact, the incorporation of $\left[{ }^{14} \mathrm{C}\right]$ glycine into uric acid in man represents the cumulative activity of de novo purine synthesis, purine nucleotide degradation, and hypoxanthine reutilization (Fig. 1). The quantitation of purine nucleotide degradation and hypoxanthine reutilization without a direct influence from purine synthesis 
de novo is possible with the administration of $\left[8-{ }^{14} \mathrm{C}\right]-$ adenine in man. Isotopic adenine given to rats and rabbits is distributed in the adenine nucleotide pool of many organs (35-38) with more rapid uptake into tissues with a high rate of cellular turnover such as intestine, bone marrow, and spleen $(36,37)$. Isotopic adenine may have a similar metabolic rate in man $(13-15,39)$.

A daily urinary excretion of $0.8 \%$ of the administered radioactivity results from the turnover of the labeled adenine nucleotide pool and agrees with previous observations (13-15). A fourfold increase of urinary radioactivity excretion occurs in patients with LeschNyhan syndrome (Fig. 2) and support the role of impaired hypoxanthine salvage in the purine overexcretion associated with hypoxanthine-guanine phosphoribosyltransferase deficiency in vivo. A similar mechanism was recently suggested for the overexcretion of purine by enzyme-deficient cells in vitro (40). Our data do not support the possibility that the increased radioactivity excretion in hypoxanthineguanine phosphoribosyltransferase deficiency results from an elevated rate of adenine nucleotide degradation. In this enzyme-deficiency state, the increased amount of total purine excretion and the normal rise in serum urate levels observed after an infusion of fructose (Figs. 3 and 4) indicate at least a normal capacity for the degradation of an increased substrate load. These studies do not suggest that the adenine nucleotide pool has been chronically depleted by an increased rate of degradation. Findings by other investigators of normal levels of intracellular purine nucleotides in cells from hypoxanthine-guanine phosphoribosyltransferase-deficient subjects support the premise of normal adenine nucleotide catabolism in these patients (31, 41, 42).

A decrease in the intestinal elimination of uric acid is an additional mechanism that could account for the increased excretion of urinary radioactivity in LeschNyhan syndrome. Intestinal uricolysis by bacteria in the gut accounts for the degradation of approximately one-third of the uric acid turned over every day in normouricemic subjects. The percentage of urate excreted by this route appears to increase with a rise in serum urate concentration (43-46). In a study of hypoxanthine-guanine phosphoribosyltransferase deficiency neither the complete nor partial enzyme deficiency was associated with any decrease in extra renal loss of urate (3). Thus, the major variable determining the degree of intestinal uricolysis in our experiments is the serum urate concentration. The mean serum urate values in the control and LeschNyhan patients were vitually identical ( 8.75 vs. 8.85 $\mathrm{mg} / \mathrm{dl})$. Thus, it is unlikely that altered gastrointestinal uricolysis might account for the increase in urinary radioactivity excretion observed.
The increase in inosine and hypoxanthine excretion after fructose infusion in control subjects indicates that the catabolic enzymes, purine nucleoside phosphorylase and xanthine oxidase, may become limiting for the increased substrate load imposed by the fructose infusion. In contrast, in the partial and complete deficiencies of hypoxanthine-guanine phosphoribosyltransferase, uric acid comprises the major fraction of the observed urinary purine rise after fructose infusion. This altered pattern of urinary purine excretion may indicate an increased activity of hepatic xanthine oxidase and purine nucleoside phosphorylase. In enzyme-deficient patients this may result in response to chronically elevated substrate levels for these two enzymes. The previous observation of a 12-fold elevation of hepatic xanthine oxidase in a patient with gout and a partial deficiency of hypoxanthineguanine phosphoribosyltransferase provides evidence to support the latter hypothesis (47).

The data described suggest that the increased rate of radioisotope excretion after $\left[8-{ }^{14} \mathrm{C}\right]$ adenine administration in hypoxanthine-guanine phosphoribosyltransferase deficiency represents decreased reutilization of hypoxanthine. From these observations, estimations concerning the role of hypoxanthine salvage are possible. The control subjects with normal erythrocyte hypoxanthine-guanine phosphoribosyltransferase levels excrete $5.6 \pm 2.4 \%$ of the infused radioactivity per week. In contrast, patients with the Lesch-Nyhan syndrome and an inability to reutilize hypoxanthine excrete $22.3 \pm 4.7 \%$ of the infused radioactivity per week. This $16.7 \%$ difference in radioactivity excretion between the normal and Lesch-Nyhan patients represents that portion of purine break down products that are normally reutilized via the salvage pathway. Such numbers lead to the estimation that $\cong 75 \%[(16.7 / 22.3) \times 100]$ of hypoxanthine is normally reutilized each day.

The loss of the ability to reutilize hypoxanthine in Lesch-Nyhan syndrome represents the absence of an important mechanism for nucleotide homeostasis. Because there is no evidence for an altered nucleotide pool in this disorder $(31,41,42)$, an increase in de novo purine synthesis must occur to maintain normal intracellular nucleotide concentrations. Thus, two separate influences drive de novo purine synthesis in Lesch-Nyhan syndrome: $(a)$ an increased intracellular concentration of phosphoribosylpyrophosphate, as a result of the absence of hypoxanthine-guanine phosphoribosyltransferase activity, and $(b)$ a failure to reutilize hypoxanthine that results in the loss of a normal major source of intracellular nucleotide synthesis.

\section{ACKNOWLEDGMENTS}

The authors wish to thank Chris Willis and other nurses at the Clinical Research Center for their devoted help in carrying 
out clinical studies; Janice Kaminska, Sally Jones, and Karin Timour for their excellent technical assistance; and the Rackham Arthritis Research Unit for secretarial support in typing this manuscript.

Supported by grants from the U. S. Public Health Service AM 19674 and 5 MOl RR-42.

\section{REFERENCES}

1. Kelley, W. N., and J. B. Wyngaarden. 1978. The LeschNyhan syndrome. In The Metabolic Basis of Inherited Disease. J. B. Stanbury, J. B. Wyngaarden, and D. S. Fredrickson, editors. McGraw-Hill Book Co., New York. 4th edition. 1011-1036.

2. Lesch, M., and M. L. Nyhan. 1964. A familial disorder of uric acid metabolism and central nervous system function. Am. J. Med. 36: 561-570.

3. Kelley, W. N., M. L. Greene, F. M. Rosenbloom, J. F. Henderson, and J. E. Seegmiller. 1969. Hypoxanthineguanine phosphoribosyltransferase deficiency in gout. Ann. Intern. Med. 70: 15.5-206.

4. Nyhan, W. L., W. J. Oliver, and M. Lesch. 1965. A familial disorder of uric acid metabolism and central nervous system function. II. J. Pediatr. 67: 257-263.

5. Kelley, W. N., F. M. Rosenbloom, and J. E. Seegmiller. 1967. The effects of azathioprine (Imuran) on purine synthesis in clinical disorders of purine metabolism. J. Clin. Invest. 46: 1518-1529.

6. Fox, I. H., and W. N. Kelley. 1972. Studies on the mechanism of fructose induced hyperuricemia in man. Metab. Clin. Exp. 21: 713-721.

7. Edwards, N. L., E. W. Gelfand, D. Biggar, and I. H. Fox. 1978. Partial purine nucleoside phosphorylase deficiency: studies of purine and pyrimidine metabolism. J. Lab. Clin. Med. 91: 736-749.

8. Kelley, W. N., F. M. Rosenbloom, J. F. Henderson, and J. E. Seegmiller. 1967. A specific enzyme defect in gout associated with overproduction of uric acid. Proc. Natl. Acad. Sci. U. S. A. 57: 1735-1739.

9. Liddle, L., J. E. Seegmiller, and L. Laster. 1959. The enzymatic spectrophotometric method for determination of uric acid. J. Lab. Clin. Med. 54: 903-913.

10. Klinenberg, J. R., S. Goldfinger, K. H. Bradley, and J. E. Seegmiller. 1967. An enzymatic spectrophotometric method for the determination of xanthine and hypoxanthine. Clin. Chem. 13: 834-846.

11. Technicon AutoAnalyzer $R$ method file. 1969. Method N 116. Technicon Instruments Corp., Tarrytown, New York.

12. Lowry, O. H., N. J. Rosebrough, A. L. Farr, and R. J. Randall. 1951. Protein measurement with Folin phenol reagent. J. Biol. Chem. 193: 265-275.

13. Wyngaarden, J. B., J. E. Seegmiller, L. Laster, and A. E. Blair. 1959. Utilization of hypoxanthine, adenine and 4-amino-5-imidazole-carboxamide for uric acid synthesis in man. Metab. Clin. Exp. 8: 455-464.

14. Ayvazian, J. H., and S. Skupp. 1965. The study of purine utilization and excretion in a xanthinuric man. J. Clin. Invest. 44: 1248-1260.

15. Bartlett, G. R. 1977. Metabolism by man of intravenously administered adenine. Transfusion (Paris). 17: 367-363.

16. Perheentupa, J., and K. O. Raivio. 1967. Fructose-induced hyperuricemia. Lancet. II: 528-531.

17. Maenpaa, P. H., K. O. Raivio, and M. P. Kekomaki. 1968. Liver adenine nucleotides; fructose-induced depletion and its effect on protein synthesis. Science (Wash.D. C.). 161: 1253-1255.

18. Burch, H. B., O. H. Lowry, L. Meinhardt, P. Mac, Jr., and K. Chyu. 1970. Effect of fructose, dihydroxyacetone glycerol, and glucose on metabolites and related compounds in liver and kidney. J. Biol. Chem. 245: 2092-2102.

19. Woods, H. F., L. V. Eggleston, and H. A. Krebs. 1970. The cause of hepatic accumulation of fructose-l-phosphate in fructose loading. Biochem. J. 119: 501-510.

20. Simkin, P. A. 1972. Hexose infusions in cebus monkeys: effects on uric acid metabolism. Metab. Clin. Exp. 21: 1029- 1036.

21. Bode, J. C., O. Zelder, H. J. Rumpelt, and U. Wittkamp. 1973. Depletion of liver adenosine phosphates and metabolic effects of intravenous infusion of fructose or sorbitol in man and in the rat. Eur. J. Clin. Invest. 3: 436-441.

22. Narins, R. G., J. S. Weisberg, and A. R. Meyers. 1974. Effects of carbohydrate on uric acid metabolism. Metab. Clin. Exp. 23: 455-465.

23. Raivio, K. O., M. A. Becker, L. J. Meyer, M. L. Greene, G. Nuki, and J. E. Seegmiller. 1975. Stimulation of human purine synthesis de novo by fructose infusion. Metab. Clin. Exp. 24: 861-869.

24. Schwarzmeier, J. D., M. M. Muller, and W. Marktl. 1977. Studies on the effect of fructose and xylitol in the rat liver: $5^{\prime}$-nucleotidase, adenosine deaminase, de novo purine synthesis. Adv. Exp. Med. Biol. 76A: 542-552.

25. Williams, W. J., and J. M. Bucham. 1953. Biosynthesis of the purine $V$. Conversion of hypoxanthine to inosinic acid by liver enzymes. J. Biol. Chem. 203: 583-593.

26. Goldwasser, E. 1954. The enzymic conversion of adenine to adenosine phosphates. Biochem. Biophys. Acta. 13: 341-346.

27. Fontenelle, L. J., and J. F. Henderson. 1969. An enzymatic basis for the inability of erythrocytes to synthesize purine nucleotides de novo. Biochem. Biophys. Acta. 177: 175- 176.

28. Lajtha, L. G., and J. R. Vane. 1958. Dependence of bone marrow cells on the liver for purine supply. Nature (Lond.). 182: 191-192.

29. Raivio, K. O., and J. E. Seegmiller. 1970. The role of phosphoribosyltransferase in purine metabolism. Curr. Top. Cell. Regul. 2: 201-225.

30. Seegmiller, J. E., F. M. Rosenbloom, and W. N. Kelley. 1967. An enzyme defect associated with a sex linked human neurological disorder and excessive purine synthesis. Science (Wash. D. C.). 155: 1682-1684.

31. Rosenbloom, F. M., J. F. Henderson, I. C. Caldwell, W. N. Kelley, and J. E. Seegmiller. 1968. Biochemical basis of accelerated purine biosynthesis de novo in human fibroblasts lacking hypoxanthine-guanine phosphoribosyltransferase. J. Biol. Chem. 243: 1166-1173.

32. Wood, A. W., M. A. Becker, and J. E. Seegmiller. 1973. Purine nucleotide synthesis in lymphoblasts cultured from normal subjects and a patient with Lesch-Nyhan syndrome. Biochem. Genet. 9: 261-274.

33. Lever, J. E., G. Nuki, and J. E. Seegmiller. 1975. Expression of purine overproduction in a series of 8-azaguanine-resistant diploid human lymphoblast lines. Proc. Natl. Acad. Sci. U. S. A. 71: 2679-2683.

34. Fox, I. H., and W. N. Kelley. 1971. Phosphoribosylpyrophosphate in man: biochemical and clinical signifcance. Ann. Intern. Med. 74: 424-433.

35. Brown, G. B., P. M. Roll, A. A. Plentl, and L. F. Cavalieri. 1948. The utilization of adenine for nucleic acid synthesis and as a precursor of guanine. J. Biol. Chem. 172: 469-484.

36. Bennett, E. L., and B. J. Krucebel. 1955. Renewal of nucleotides and nucleic acids in $C_{57}$ mice studied with adenine-4,6-14 $\mathrm{C}_{1}$. Biophys. Biochem. Acta. 17: 503-514.

37. Sartorelli, A. C., and G. A. LePage. 1958. Metabolic 
effects of 6-thioguanine. II. Biosynthesis of nucleic acid purines in vivo and in vitro. Cancer Res. 18: 1329-1335.

38. Bartlett, G. R. 1977. Metabolism by the rabbit of intravenously administered adenine. Transfusion (Paris). 17: $351-357$.

39. Seegmiller, J. E., J. R. Klinenberg, J. Miller, and R. W. E. Watts. 1968. Suppression of glycine $-{ }^{15} \mathrm{~N}$ incorporation into urinary uric acid by adenine- $-8{ }^{13} \mathrm{C}$ in normal and gouty subjects. J. Clin. Invest. 47: 1193-1202.

40. Hershfield, M. S., E. B. Spector, and J. E. Seegmiller. 1977. Purine synthesis and excretion in mutants of the W1-L2 human lymphoblast line deficient in adenosine kinase (AK) and adenine phosphoribosyltransferase (APRT). Adv. Exp. Med. Biol. 76A: 303-313.

41. Nuki, G., K. Astrin, D. P. Brenton, M. K. Cruikshank, J. Lever, and J. E. Seegmiller. 1977. Purine and pyrimidine concentration in cells with decreased hypoxanthineguanine phosphoribosyltransferase activity. Adv. Exp. Med. Biol. 76A: 326-339.
42. Brenton, D. P., K. H. Astrin, M. K. Cruikshank, and J. E. Seegmiller. 1977. Measurement of free nucleotides in cultured human lymphoid cells using high pressure liquid chromatography. Biochem. Med. 17: 231-247.

43. Buzard, J., C. Bishop, and J. H. Talbott. 1955. The fate of uric acid in the normal and gouty human being. $J$. Chronic. Dis. 2: 42-49.

44. Sorensen, L. B. 1959. Degradation of uric acid in man. Metab. Clin. Exp. 8: 687-703.

45. Pollycove, M., B. M. Tolbert, J. H. Lawrence, and D. Harman. 1957. Uric acid metabolism: the oxidation of uric acid in normal subjects and patients with gout, polycythemia, and leukemia. Clin. Res. Proc. 5: 38-39.

46. Sorensen, L. B. 1962. The pathogenesis of gout. Arch. Intern. Med. 109: 379-390.

47. Carcassi, A. 1977. Xanthine oxidase activity in a gouty patient with a partial deficiency of HGPRT. Adv. Exp. Med. Biol. 76A: 346-350. 